\title{
Retributivism and the proportionality dilemma
}

\section{Ryberg, Jesper}

\section{Published in:}

Ratio. An International Journal of Analytic Philosophy

DOI:

10.1111/rati.12297

\section{Publication date:}

2021

\section{Document Version}

Early version, also known as pre-print

Citation for published version (APA):

Ryberg, J. (2021). Retributivism and the proportionality dilemma. Ratio. An International Journal of Analytic Philosophy, 34(2), 158-166. https://doi.org/10.1111/rati.12297

\section{General rights}

Copyright and moral rights for the publications made accessible in the public portal are retained by the authors and/or other copyright owners and it is a condition of accessing publications that users recognise and abide by the legal requirements associated with these rights.

- Users may download and print one copy of any publication from the public portal for the purpose of private study or research.

- You may not further distribute the material or use it for any profit-making activity or commercial gain.

- You may freely distribute the URL identifying the publication in the public portal.

\section{Take down policy}

If you believe that this document breaches copyright please contact rucforsk@kb.dk providing details, and we will remove access to the work immediately and investigate your claim. 


\title{
Important note from the Publisher:
}

"This is the pre-peer reviewed version of the following article: Ryberg, J. Retributivism and the proportionality dilemma. Ratio. 2021; 34: 158-166, which has been published in final form at https://doi.org/10.1111/rati.12297. This article may be used for non-commercial purposes in accordance with Wiley Terms and Conditions for Use of Self-Archived Versions."

\section{Retributivism and the Proportionality Dilemma}

Jesper Ryberg

\author{
Pre-print
}

\begin{abstract}
'Retributivism' covers a wide range of theories which, even though they differ in various ways, all give some room for proportionality considerations with regard to the question of how severely offenders should be punished. This article addresses the question - well-known from traditional ethical theory - as to whether proportionality constraints should be given an absolutist or a nonabsolutist interpretation. It is argued that both absolutist and some non-absolutist accounts of proportionality constraints have counter-intuitive implications and, more generally, that the nonabsolutist interpretation, to which most retributivists seem to subscribe, faces serious challenges with regard to how the thresholds of such constraints should be determined. It is concluded that, given the aspiration of providing genuine action guidance for penal practice, the retributivist faces a dilemma that is not easily resolved.
\end{abstract}

\section{Key words}

constraints; deontology; punishment; proportionality; retributivism. 


\section{INTRODUCTION}

The ethics of punishment constitutes a field of research characterized by widespread theoretical disagreement. For instance, despite the fact that introductory presentations of the theoretical field sometimes leave the opposite impression, it is a well-known fact that 'retributivism' does not denote a single theory of punishment. ${ }^{1}$ Rather, the term covers a wide range of theories which - even if they all regard the just deserts of an offender as playing a lead moral role - may be of very different shape. For instance, retributivist theories differ significantly in the way these theories constrain the significance of consequences in the determination of what constitutes the proper punishment for a particular crime. According to negative retributivist theories, there is, for a crime of a certain degree of seriousness, an upper proportionality constraint which should not be transgressed. However, below this upper limit, the precise punishment should be determined on the grounds of consequentialist considerations. $^{2}$ For so-called limiting retributivists, there are both upper and lower limits which leave a range within which consequentialist considerations should help in fine-tuning the precise punishment for the crime in question. For positive retributivists these two types of limits coincide in the sense that it would be impermissible to punish either more severely or less severely than the particular punishment that reflects the severity of the crime that has been committed. Which of these accounts of retributivist theory is most plausible is not a question that will be addressed here. Rather, the question that will be considered cuts across the different accounts: namely, what do such

\footnotetext{
${ }^{1}$ For presentations of various accounts of retributivism, see e.g. Cottingham (1979); Duff (1986); Duff \& Hoskins (2019); Ten (1987); Walen (2016); Walker (1999); White (2011).

${ }^{2}$ Some theorists would prefer to refer to theories in this category as side-constrained consequentialist theories. See, for instance, Duff (2001).
} 
constraints more precisely imply? More specifically, should retributivist proportionality constraints be given an absolutist or a non-absolutist interpretation?

The distinction between absolutist and non-absolutist interpretations of moral constraints constitutes one of the basic ingredients in standard ethical theory. In fact, it is probably one of the first distinctions to which students of ethics are introduced in courses providing an initial overview of the contents of deontological and consequentialist ethics. Moreover, at the academic level numerous works have been written on absolutist and moderate deontology and, hence, on what constitutes the most plausible interpretation of ethical constraints (see e.g. Alexander, 2000; Alexander \& Moore, 2016; Ellis, 1992; Kagan, 1997). In this light, it is surprising how little attention has been devoted to the discussion of this distinction in relation to retributivist proportionality constraints. Whether such constraints should be interpreted in absolutist or non-absolutist terms is often something which is only very briefly mentioned in passing without engaging in more thorough considerations of what would sustain one interpretation rather than another and, not least, of what the distinction implies for the application of retributivist theory in criminal justice practice. The purpose of this article is to consider these questions. More specifically, it will be argued that both absolutist and non-absolutist interpretations of proportionality constraints face challenges and, therefore, that retributivists are confronted with a serious dilemma. In order to develop and buttress this contention, the article will proceed as follows. In section (2), a standard objection against an absolutist interpretation of proportionality constraints is presented. Section (3) subsequently considers the theoretical challenges that arise in relation to the question of how thresholds should be determined if one subscribes to a non-absolutist interpretation of proportionality constraints. Section (4) is devoted to methodological considerations on how retributivists could possibly resolve the dilemma that neither of the two interpretations considered in the previous sections seem to constitute tenable positions. Finally, section (5) summarizes and concludes. 
However, before embarking on these considerations, a number of minor points of clarification should be made concerning the contents and scope of the discussion. First, I will not engage in the definitional discussion of whether a theory based on a threshold interpretation of proportionality constraints should still be seen as a deontological theory or whether this term, as some theorists have suggested, should only be reserved for theories invoking absolute constraints (Smilansky, 2003; but also Cook, 2018). Linguistics is not the arbiter in philosophy and nothing in the following discussion hinges on this terminological point. Thus, I will simply stick to what I believe constitutes current standard terminology, namely, to refer to positions advocating nonabsolutist interpretations of constraints as 'moderate deontological theories'. Second, the discussion in the following does not presuppose a view on the deontic implications in cases where the consequences of a punishment are sufficiently weighty to override a deontological constraint - that is, whether such punishments should be seen as obligatory or merely permissible. Thus, in the following I will simply go along with the weaker interpretation by talking about the permissibility of punishing in a disproportionate manner. Third, some retributivists distinguish between a constraint against punishment of innocents and a constraint against disproportionate punishment of offenders (Lippke, 2014). Others seem to regard the punishment of innocents simply as a special instance of a disproportionate punishment (the innocent is being over-punished since he or she should not have been punished at all). The present discussion does not depend upon whether or not one regards it as important to make such a distinction. Thus, for reasons of ease of exposition, in the following I will assume that constraints against disproportionate punishment also cover cases involving punishment of innocents. Fourth, the discussion in this article will not be addressing the traditional question as to whether the existence of proportionality constraints can consistently be defended as delivering the theoretical foundation of a penal system which, in practice, will inadvertently end up punishing some offenders in a disproportionate manner (see Lempert, 1981; Ryberg, 2004). In other words, the 
present discussion will not focus on the moral significance of foreseen miscarriages of justice, but only on when it is permissible to intentionally violate proportionality in punishment. Finally, even though the ensuing discussion reflects the more general ethical debate on the plausibility of absolutist and moderate versions of deontology, I do not wish to suggest that the considerations presented can be extrapolated directly into conclusions at the more general level of ethical theory. In other words, what I am interested in here is not the structure of deontological ethics in general but, more narrowly, the nature of retributivist proportionality constraints.

\section{ABSOLUTE PROPORTIONALITY CONSTRAINTS}

The theoretically simplest way of interpreting the view that there are upper and perhaps lower constraints on how severely someone who has committed a crime of a certain degree of seriousness should be punished is to regard proportionality constraints as absolute. For instance, from a positive retributivist perspective, the proper punishment of a particular burglar might be neither more nor less than one year in prison. For a negative or limiting retributivist, the burglar might be punished less than one year if there are consequentialist reasons for doing so, but never more than one year in prison. But the important thing is that these punitive restrictions do not allow for exceptions. From the absolutist point of view, such constraints should be observed, whatever the consequences. ${ }^{3}$

It is precisely this rigorist lack of exceptions that has generally led many deontologists to abandon absolutism and, correspondingly, motivated many of those retributivists who have commented on the issue to adopt a moderate position. It is not difficult to imagine examples that strongly challenge the absolutist conception of proportionality constraints. For instance, if a murderer deserves 20 years in prison, but it would be possible to prevent a serious terrorist attack that would

\footnotetext{
${ }^{3}$ The absolutist view is, of course, traditionally ascribed to Kant, who warns each man against creeping through the 'serpent-windings of utilitarianism to discover some advantage that may discharge him from the justice of punishment or even from the due measure of it, according to the Pharisaic maxim: 'It is better that one man should die than the whole people should perish"' (see Ryberg, 2004, p. 44).
} 
result in the killing of thousands of citizens only if this murderer were to be kept behind bars for one extra day (or perhaps one extra hour), then it seems hard to believe this would be morally impermissible. Similarly, if the lower proportionality constraint for a minor theft is a $\$ 600$ fine and if, for some reason, it would be possible to prevent the terrorist attack only by inflicting a slightly lower fine, say $\$ 590$ (or perhaps $\$ 599$ ), then it seems highly counter-intuitive to suggest that the imposition of this disproportionately lenient punishment would be morally impermissible. ${ }^{4}$

Although the question of the moral significance of such reductio arguments, which we will return to later, opens up several more basic questions on ethical methodology, it is worth noting that it is reasonable to believe that many retributivists would be sensitive to such counter-examples. The reason is simply that retributivists have typically objected to consequentialist approaches to punishment precisely on such grounds. In the predominantly utilitarian-oriented 1960s, John McCloskey presented his objection against the utilitarian theory of punishment (McCloskey, 1962; 1965). McCloskey envisioned the scenario of a town with a mixed population in which a black man has raped a white woman and where the only way to prevent the outbreak of subsequent serious racial violence would be for the local Sheriff to frame an innocent black man who was seen close to the place where the crime happened. According to McCloskey, the utilitarian theory of punishment implies that the innocent person should be punished, which he regards as morally absurd. Hence, the utilitarian theory should be rejected. This argument has subsequently - in slightly different versions - been repeated over and over again by leading retributivists. But if retributivists accept such intuition-driven counter-arguments, then obviously they would themselves be equally vulnerable if their own theory suffers from counter-intuitive implications. And, arguably, it is precisely in this

\footnotetext{
${ }^{4}$ Obviously, the fact that one subscribes to an absolutist interpretation of the impermissibility of upward deviations from what proportionality prescribes need not commit one to the view that downward deviations are always impermissible. Some retributivists seem to believe that downward deviations may sometimes be permissible while this is not the case for upward deviations. However, a principled, justice-based argument to this effect has not, to my knowledge, been provided (but see Duus-Ötterström, 2013).
} 
category that the implications that one should abstain from keeping a murderer behind bars for an extra day or from fining a thief $\$ 10$ less than what proportionality dictates - even if these were the only ways to avoid thousands of casualties in a terrorist attack - would seem to belong. As Anthony Ellis has put it in his general discussion of the structure of deontological ethics, the view 'that absolutely nothing could justify infringing a deontological rule, even a very stringent one, seems excessively hard to believe' (Ellis, 1992, p. 2). As indicated, it seems appealing to hold that this conclusion also applies with regard to the absolutist interpretation of proportionality constraints. However, luckily for the retributivist, there has been a traditional escape route.

\section{NON-ABSOLUTIST PROPORTIONALITY CONSTRAINTS}

Many influential deontologists explicitly reject absolutism in favor of a moderate position invoking a threshold interpretation of moral constraints. The general intention behind such moderate positions is to capture both the intuition that there are some actions that ought not to be performed and the intuition that valid moral rules can be legitimately subverted in sufficiently extreme circumstances (see Ellis, 1992, p. 2). This idea is also found in expositions of modern versions of retributivism. ${ }^{5}$ Though a proportionality constraint should usually be carefully observed, there may be circumstances under which the consequences become sufficiently dire and where this constraint, therefore, can be permissibly infringed.

The idea that there is a threshold above which the intrinsic wrongness of an action is trumped by considerations of consequences has, in the more general discussion of deontology, been subjected to different types of criticism. The purpose here is not to provide an overview of this general discussion but, more modestly, to direct attention to what seems to constitute the most obvious question to the moderate interpretation of proportionality constraints, namely: How should such

\footnotetext{
${ }^{5}$ See, for instance, Alexander, Ferzan, \& Morse (2011); Moore (1997); Primoratz (1998); von Hirsch (1993).
} 
thresholds be determined? This question, as we shall now see, does not seem to open for an easy answer.

The first thing that complicates the question is that it is difficult to see what the contours of an answer would look like. One possibility might be to hope that an answer could be derived directly from a closer analysis of retributive theory - that is, of the explanations of why offenders deserve punishment and should be punished in a proportionate manner. I cannot here go through all current variants of retributivist positions, but it seems quite clear that what these theories all attempt is precisely to explain why offenders deserve punishment, not why it is permissible to deviate from what retributive justice requires. ${ }^{6}$ It seems almost naïve to believe that it would be possible to strictly deduce from a retributivist theory - such as, for instance, so-called unfair advantage theories or expressionist theories - what precisely constitutes the proper setting for a threshold (e.g. that it would require at least the prevention of 122 future instances of theft in order to make it permissible to punish a current thief in a way that deviates from what proportionality prescribes). ${ }^{7}$ The basic retributivist theories simply do not contain the sort of theoretical ingredients that would make deductions of such a degree of precision possible. But if this observation is correct, then what is the alternative? How could the moderate retributivist possibly hope to reach an answer? As far as I can see, the only possible answer would be to hold that thresholds should be determined on the grounds of intuition. As we have seen, the impetus behind the moderate deontological position is precisely to provide a theory which is intuitively more acceptable than absolutist accounts. Moreover, it is widely

\footnotetext{
${ }^{6}$ I do not know of any theorists in the modern retributivist era who have tried to specify where the threshold for different crimes should be located or who have attempted to develop a theoretical framework for the determination of thresholds.

${ }^{7}$ As we will return to shortly, the theoretical determination of thresholds would not only be complicated by the fact that such determination requires a very high degree of precision, but probably also by the fact that the location of a threshold would be contingent both on the seriousness of the crime and the degree to which a proportionality constraint has been infringed (e.g. the extent to which an offender is being overpunished).
} 
acceptable in ethical methodology that there should be some room for moral intuition. Would this thus constitute a plausible approach for the moderate retributivist?

In order to answer this question, it is first necessary to take a closer look at what it means to ask where a threshold is located. A useful distinction in this connection is the one between what Larry Alexander and Michael Moore refer to as respectively a 'fixed threshold' and a 'sliding scale threshold' (Alexander \& Moore, 2016). A threshold in the former category is one that is fixed in the sense that it does not vary along any dimension such as the degree to which a certain constraint is being violated. For instance, in terms of proportionality constraints, this would mean that it requires the same magnitude of countervailing consequences to make it permissible to punish a murderer, who deserves 20 years in prison, for an extra day as it does to impose a 20 -year prison term on an innocent person. Both are cases of over-punishment and, therefore, require countervailing reasons of the same magnitude to become morally permissible. Conversely, according to an account involving sliding scale thresholds, the latter case of over-punishment constitutes a much more severe violation of the proportionality constraint and, therefore, requires much stronger countervailing reasons in order for it to be morally permissible. Which of these two interpretations should the moderate retributivist opt for? As will now be argued, I believe the answer is that they both face serious problems.

Consider first the fixed threshold account. If it is correct that the only genuine option for the retributivist is to determine thresholds on the grounds of intuition, then this account does not seem to constitute the preferable option. The reason, obviously, is that invariance with regard to level does not seem to fit our intuition. As just indicated, I take it that most would intuitively agree that it requires much stronger countervailing reasons to punish an innocent (or a pickpocket) with 20 years in prison than to punish a murderer for an extra day beyond the 20 years he or she may rightly deserve. Furthermore, and even more importantly, the fixed threshold account faces that same problem as the absolutist account. In order for it to be permissible to punish an innocent (or a pickpocket) with 20 
years behind bars, this will presumably require very strong countervailing reasons. That is, a threshold located at a very high level. But if this high level is fixed for all violations of proportionality constraints, then, as we have seen in relation to the absolutist account, this opens up to counterintuitive implications in those cases involving only marginal proportionality deviations. As noted, it seem very hard to believe that it would be impermissible to punish a murderer for a day, or perhaps an hour, more than he or she deserves, or fine a thief $\$ 10$ or perhaps $\$ 1$ less than what proportionality prescribes, if these were the only ways to avoid an outcome involving the loss of the lives of hundreds of people. Thus, for both of the outlined reasons the fixed threshold account does not seem promising. But then, what about the idea of sliding thresholds? Is it not the case that this interpretation is designed precisely to account for the outlined conflicting intuitions facing the idea of fixed thresholds? If, as suggested, the only proper way to determine a threshold is to draw on our intuitive judgements, then, as we shall now see, this account also turns out to be problematic, though for somewhat different reasons.

The overall problem is that it is far from clear what it means to hold that thresholds should be intuitively determined. One way of understanding this would be to suggest that the question of when are consequences sufficiently weighty to justify that a proportionality constraint is overridden depends upon the intuition of the individual decision-maker. Thus, if a sentencing judge finds that in a particular case the countervailing reasons are sufficiently strong to justify the over- or under-punishment of an offender, then such a violation of proportionality would be permissible. However, on this account there is no requirement or guarantee of any kind of consistency. Thus, if the intuition of one judge deviates from the intuition of another, then two offenders who have committed the same crimes might end up being punished very differently even when the 
countervailing reasons are equally strong. ${ }^{8}$ This seems morally arbitrary and hard to accept (in particular, I take it, for positive retributivists, who have traditionally strongly advocated the significance of parity in sentencing). But if this is not what it means to determine thresholds intuitively - that is, if this idea also requires some sort of consistency - then things become theoretically more complicated.

First, do we have any clear intuition at all of where a threshold should be located? For instance, do we have an intuition of the kind that the prevention of 42 instances of future burglaries is insufficient to justify over-punishment of a current burglar, while the prevention of 43 instances would tip the scale and make the over-punishment permissible? I must admit that we do not have intuitions of the kind of precision which a threshold arguably presupposes. ${ }^{9}$ Moreover, as we shall now see, real life comparisons may well be much less simple.

Second, how should one consistently compare the magnitude of countervailing reasons that may take very different forms? In standard considerations of moderate deontology, it has often been asked how many lives one would have to rescue in order to justify the intentional killing of single individual. But obviously, in real life - such as in criminal justice practice - the countervailing reasons can take very different forms and be difficult to compare. For example, what if the overpunishment of a burglar can prevent 100 future instances of burglary, and in another case, 20 instances of rape, and in a third case, 5 murders? Should one then engage in some sort of utilitarian calculus of how many instances of one type of crime corresponds in aggregated well-being to a certain number of other crimes? And would the idea then be that one should produce some sort of matrix of how a

\footnotetext{
${ }^{8}$ It might be suggested that consistency would follow from the fact that the intuitive judgment of a judge would provide a precedent for other judges to follow in their sentencing decisions. However, it seems somewhat arbitrary to hold that it is the intuition of the first sentencing judge that should determine where thresholds are located even if other judges have diverging intuitive judgements.

${ }^{9}$ It might be suggested that what we need is not a precise threshold, but only some sort of 'grey-zone'. However, this answer is of little help. The problem is that one will have to answer when the grey-zone starts and ends. Therefore, as is well known from discussions of vagueness and the sorites paradox in philosophy of language, such an approach doubles the problem of drawing a precise limit (see also Ryberg 2010).
} 
certain number of one type of crime can be translated into numbers of other crimes of varying gravity? And, if so, how should one cope with the fact that crimes within the same category may sometime differ significantly in gravity or that over-punishment may also have many other types of effects beyond those related to crime prevention? As this indicates, the determination of thresholds in a field where the countervailing reasons may take various forms is not an easy task.

Third, the whole idea of sliding thresholds is that the setting for a threshold varies along certain dimensions (see Kagan, 1987). For instance, it might intuitively be regarded as more wrongful - and thus as requiring stronger countervailing reasons - to impose a week of imprisonment beyond the punishment that a thief deserves than to over-punish a murderer to the same extent. Furthermore, the setting of the threshold would at least be contingent on the extent to which a constraint is violated. That is, it would require stronger countervailing reasons to justify over-punishing an offender for an extra year beyond what is deserved than to over-punish the offender by imposing an extra week behind bars. But if the threshold varies with such dimensions, what precisely is it that should be intuitively assessed in a system which also requires some degree of consistency? Is it the idea that one should find an overall function describing how thresholds vary with the severity of crimes and the extent to which proportionality thresholds are exceeded? If so, do we have any intuition about the preferable shape of such general functions? And what if there are interpersonal variations in the intuitive judgements? The contention that threshold should be determined on the grounds of intuition may seem a comfortable resort in cases where it is hard to believe that answers could be derived directly from the contents of retributivist theory. However, as these questions indicate, the answer seems much less attractive once one starts considering what precisely it is that should be intuitively determined, particularly if one accepts that our intuitive judgements must also be subjected to some sort of minimal consistency requirements. 
So where do the above considerations lead us? What we have considered are the challenges facing the threshold interpretation of retributivist proportionality constraints. It was suggested that it is difficult to imagine how thresholds can possibly be determined in other ways than by reference to moral intuition. ${ }^{10}$ However, if this is correct, then, on the one hand, an interpretation involving fixed proportionality threshold does not seem to constitute an attractive option. This interpretation is counterintuitive in various ways. On the other hand, an interpretation invoking sliding thresholds makes it hard to specify precisely how a threshold should be intuitively determined - in particular, if some sort of consistency requirement should be upheld, as seems reasonable. Thus, even though the threshold view prima facie seems to constitute an attractive alternative to the absolutist interpretation, on closer scrutiny, it is encumbered with several challenges of its own.

\section{HOW MIGHT THE RETRIBUTIVIST RESPOND?}

The absolutist and the non-absolutist positions exhaust the logical space of the possible interpretations of proportionality constraints. But this means that if the previous considerations are correct, then retributivists are faced with the dilemma that none of the possible interpretations seem to constitute attractive positions. Where does this leave the retributivist? As will become clear, I do not wish to suggest that the objections that have been raised constitute knock-down arguments against the idea of proportionality constraints. There are ways in which the retributivist might proceed which we have not yet considered. The purpose of this section, therefore, is to briefly outline the two routes the

\footnotetext{
${ }^{10}$ It might perhaps be suggested that the previous considerations are too tough on the moderate retributivist. Afterall, if there are problems associated with the reference to moral intuitions, these problems might just as well constitute challenges to other theories of punishment. However, in my view, this answer is premature. For instance, a utilitarian might respond that one should not invoke intuitions or only a few basic intuitions (e.g. the intuition that suffering has intrinsic negative value). And an absolutist retributivist could respond by holding that he or she does not have to draw on the very precise intuitions that are required in order to determine the location of thresholds. Thus, a tu quoque defence does not seem to constitute a viable option.
} 
retributivist could choose. However, as we will see, none of these options are theoretically cost-free.

The first possibility might be to reject the counter-intuitiveness of the conclusions of the arguments that have been presented against the absolute interpretation and the fixed threshold interpretation of proportionalist constraints. If it does not strike one as morally absurd to regard minor upward or downward deviations from what proportionality constraints prescribe as impermissible even when this will have very dire consequences, then obviously several of the above arguments have lost their force. Interestingly, this strategy - sometimes referred to as the "out-smart" response - of rejecting what others take as absurd conclusions of reductio arguments has usually been rejected by retributivists when some utilitarians have held that they do not feel the intuitive bite of the McCloskeyan punishment-of-the-innocent objection. Obviously, though, a retributivist might hold that the implications of utilitarianism are counter-intuitive, while at the same time holding that this is not the case with regard to objections pointing to the alleged absurdities of rigorously observing proportionality constraints. However, the problem is that this answer is simply not very persuasive. There are a number of retributivists who explicitly reject Kantian absolutism - sometimes expressed in the dictum fiat justitia, et ruat mundus ${ }^{11}$ - precisely because they accept that such a position has counter-intuitive implications. And, as we have seen, it is hard to believe that even a very justiceminded theorist would remain unaffected by the implication that it would be unacceptable to fine a thief $\$ 1$ more or less than what proportionality constraints imply even if this could prevent comprehensive deleterious consequences for a large number of people. Thus, even though this reply might constitute a possible escape route for the retributivist, it does not seem to constitute a viable option. And I am not aware of anyone who seriously advocates such an answer.

\footnotetext{
11 'Let the world perish so long as justice be done'.
} 
A second and perhaps more promising approach, if one is not persuaded by the objections that have been raised against absolutist interpretations and non-absolutist interpretations with a high threshold, might be to question the conclusiveness of reductio arguments. That is, it might be held that even if such accounts of proportionality constraints have counter-intuitive implications, this does not suffice to reject the theories. After all, all ethical theories seem to have some counterintuitive implications and the whole idea of developing ethical theories is precisely that there is a point in not merely following the dictate of our intuition. In fact, this answer could be elaborated and defended on the grounds of the view that the most plausible moral principles are those that constitute a reflective equilibrium between basic ethical theory, moral intuitions, and perhaps other kinds of background theories. Therefore, on the grounds of such a widely accepted methodological theory, it might be admitted that some of the interpretations of thresholds conflict with some of our moral intuitions, while at the same time contending that these interpretations nevertheless constitute the preferable candidates for principles balancing the different considerations on the grounds of which a normative theory should be assessed. By drawing on such methodological considerations to which many theorists subscribe, from the outset this answer is more promising than the former answers. However, for the retributivist this answer comes with a price. If counter-intuitive implications are insufficient to reject an ethical theory, then the retributivist will also have to abandon the standard punishment-of-the-innocent objection as sufficient grounds for rejecting a consequentialist approach of the justification of punishment. Put in more general terms, the retributivist will be faced with the broader comparative task of showing that a retributivist theory invoking a certain interpretation of proportionality constraints is the one that most convincingly satisfies the criteria of a reflective equilibrium methodology. It may be the case that this approach is methodologically on the right track. However, it is also a very incomplete defense in the sense that it remains to be shown that at the end 
of this track there is, in fact, a theory invoking proportionality constraints and not a theory of punishment of a different shape.

In summary, none of the two approaches that have been briefly considered here with regard to how the suggested dilemma confronting the retributivist should be met seem to provide fully satisfactory answers. First, rejecting that proportionality constraints face counter-intuitive implications seemed very hard to accept. Second, the fact that such implications are not sufficient to reject a moral principle may be plausible, but it basically leaves as an open question whether a theory invoking proportionality constraints should be accepted at all. Thus, even if the suggested dilemma, as noted, may not be devastating for the retributivist, the answers considered are still far from having provided this theory with anything like a more substantial theoretical remedy.

\section{CONCLUSION}

The view that deontological theories can be divided into positions holding either an absolutist or a non-absolutist interpretation of moral constraints is widely accepted in modern ethical theory. As initially noted, from this perspective it is surprising that so little attention has been directed to the task of clarifying what this distinction more precisely implies in relation to the proportionality constraints that constitute the backbone in all retributivist approaches to penal distribution. There are, as the previous discussion attests, strong reasons for considering this question more thoroughly. More precisely, what I have argued is, on the one hand, that an absolutist interpretation of proportionality constraints has implications that seem highly counter-intuitive. On the other, I have suggested that a threshold account faces serious problems. Some threshold accounts had counter-intuitive implications. And, more generally, the threshold position was confronted with the question of how thresholds should be determined. As argued, this question gives rise to several theoretical challenges. Taken together, this means that the retributivist is confronted with the dilemma that both the absolutist 
and the non-absolutist interpretation of constraints are vulnerable to objections. Furthermore, it was argued that attempts at answering these objections on the grounds of more basic methodological considerations are far from successful. Thus, it may be the case that the distinction between absolutism and non-absolutism, from the point of view of standard ethical theory, is widely accepted, easy to conceptually define, and, as such, feels almost trivial. However, when it comes to the question as to what this distinction implies for a retributivist approach to punishment - developed with the ultimate purpose of guiding criminal justice practice - this, as we have seen, is very far from being trivial. 


\section{References}

Alexander, L. (2000). Deontology at the Threshold. San Diego Law Review, 38, 893-912.

Alexander, L., Ferzan, K. K. \& Morse, S. (2011). Crime and Culpability: A Theory of Criminal Law. New York: Cambridge University Press.

Alexander, L. \& Moore, M. (2016). Deontological Ethics. Stanford Encyclopedia of Philosophy (online).

Cook, T. (2018). Deontologists Can Be Moderate. Journal of Value Inquiry, 52, 199-212. doi 10.1007/s10790-017-9608-7.

Cottingham, J. G. (1979). Varieties of Retribution. Philosophical Quarterly, 29, 238-246. doi $10.2307 / 2218820$.

Duff, A. (1986), Trials and Punishment. Cambridge: Cambridge University Press.

Duff, A, (1991). Punishment, Communication, and Community. Oxford: Oxford University Press.

Duff, A. \& Hoskins, Z. (2019). Legal Punishment. Stanford Encyclopedia of Philosophy (online).

Duus-Ötterström, G. (2013). Why Retributivists Should Endorse Lenience in Punishment. Law and Philosophy, 32, 459-483. doi 10.1007/s10982-012-9147-0.

Ellis, A. (1992). Deontology, Incommensurability and the Arbitrary. Philosophy and Phenomenological Research, 52, 855-875. doi 10.2307/2107914.

Kagan. S. (1997). Normative Ethics. Boulder: Westview Press.

Lempert, R. O. (1981). Desert and Deterrence: An Assessment of the Moral Base of the Case for Capital Punishment. Michigan Law Review, 79, 1177-1231. doi 10.2307/1288113.

Lippke, R. (2014). Some Surprising Implications Of Negative Retributivism. Journal of Applied Philosophy, 31, 49-62. doi 10.1111/japp.12044.

McCloskey, J (1962). The Complexity of the Concepts of Punishment. Philosophy, 37, 307-325. 
McCloskey, J. (1965). A Non-Utilitarian Approach to Punishment. Inquiry, 8, 249-263. doi $10.1080 / 00201746508601433$.

Moore, M. (2010). Placing Blame. Oxford: Clarendon Press.

Primoratz, I. (1998). Justifying Legal Punishment. London: Humanities Press.

Ryberg, J. (2004), The Ethics of Proportionate Punishment. Dordrecht: Kluwer Academic Publishers. Ryberg, J. (2010). Mass Atrocities, Retributivism, and the Threshold Challenge. Res Publica, 16, 169-179. doi 10.1007/s11158-010-9113-3.

Smilansky, S. (2003). Can Deontologists be Moderate? Utilitas, 15, 71-75. doi 10.1017/S0953820800003770.

Ten, C. L. (1987). Guilt and Punishment. Oxford: Clarendon Press.

von Hirsch A. (1993). Censure and Sanctions. Oxford: Clarendon Press.

Walen, A. (2016). Retributive Justice. Stanford Encyclopaedia of Philosophy (online).

Walker, N. (1999). Even More Varieties of Retribution. Philosophy, 74, 595-605.

White, M. D. (2011). Retributivism: Essays on Theory and Policy. New York: Oxford University Press. 